\title{
Institutions and Growth: a GMM/IV Panel VAR Approach
}




\title{
WP/15/174
}

\section{IMF Working Paper}

\section{Institutions and Growth: a GMM/IV Panel VAR Approach}

\author{
by Carlos Góes
}

IMF Working Papers describe research in progress by the author(s) and are published to elicit comments and to encourage debate. The views expressed in IMF Working Papers are those of the author(s) and do not necessarily represent the views of the IMF, its Executive Board, or IMF management.
I N T E R N A T I O N A L
$M O N E T A R Y$
F U N D 


\title{
IMF Working Paper
}

Western Hemisphere Department

\section{Institutions and Growth: a GMM/IV Panel VAR Approach \\ Prepared by Carlos Góes ${ }^{1}$}

Authorized for distribution by Alfredo Cuevas

July 2015

\section{IMF Working Papers describe research in progress by the author(s) and are published to elicit comments and to encourage debate. The views expressed in IMF Working Papers are those of the author(s) and do not necessarily represent the views of the IMF, its Executive Board, or IMF management.}

\begin{abstract}
Both sides of the institutions and growth debate have resorted largely to microeconometric techniques in testing hypotheses. In this paper, I build a panel structural vector autoregression (SVAR) model for a short panel of 119 countries over 10 years and find support for the institutions hypothesis. Controlling for individual fixed effects, I find that exogenous shocks to a proxy for institutional quality have a positive and statistically significant effect on GDP per capita. On average, a 1 percent shock in institutional quality leads to a peak 1.7 percent increase in GDP per capita after six years. Results are robust to using a different proxy for institutional quality. There are different dynamics for advanced economies and developing countries. This suggests diminishing returns to institutional quality improvements.
\end{abstract}

JEL Classification Numbers: O43, C33, C14.

Keywords: Institutions, Panel VAR, Economic Development.

Author's E-Mail Address: cgoes@imf.org

\footnotetext{
${ }^{1}$ International Monetary Fund (WHD). I thank Maddie Eldridge (2013) for giving me the initial insight that one should try to incorporate the feedback loops between institutions and growth to this debate, which pointed to a VAR-type analysis. I am grateful to Troy Matheson, Alfredo Cuevas, Joshua Hall, Ranae Jabri, Nicolas Magud, Roberto Ellery, Alex Herman, and Leo Feler for their helpful comments. All potential mistakes and omissions are solely mine.
} 


\section{Contents}

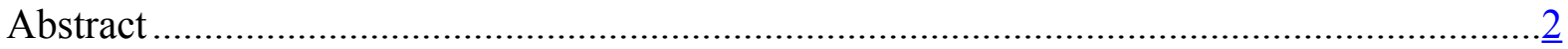

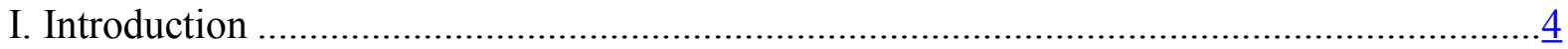

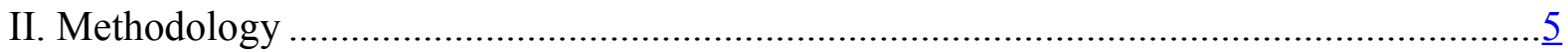

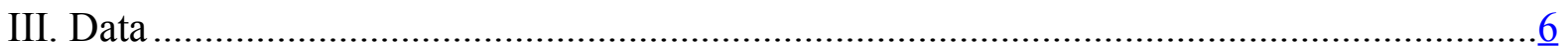

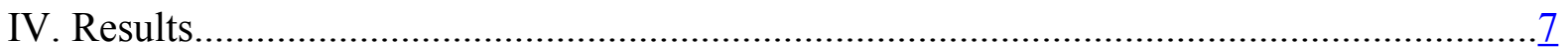

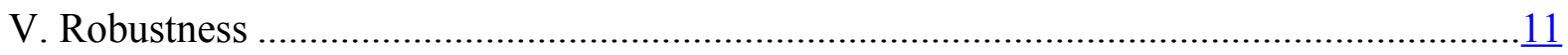

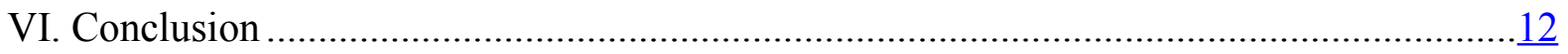

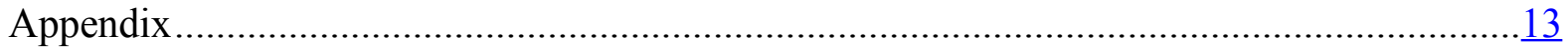

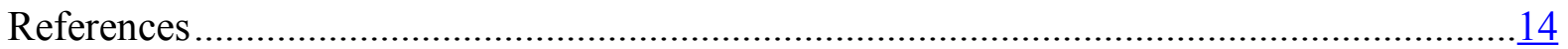




\section{INTRODUCTION}

Since Acemoglu, Johnson and Robinson's (AJR, 2001) seminal paper supporting the link between institutions and development, the debate over the role of institutions on economic growth has spurred much research. Those who are critics of institutionalism are perhaps better represented by Jeffrey Sachs (2003), who has emphasized the prevalence of ecology and geography over institutions in economic development.

However, both sides of such debate have resorted largely to microeconometric techniques in testing hypotheses. There are several reasons for that. The most important one is that complete time series of country-wide institutional quality indicators have only become available in the last fifteen years. This has limited the extent to which researchers can explore dynamics in the institutions-growth relationship since the data are still too scant for individual-country time series analysis. Additionally, although the popularity of panel vector autoregressions has been increasing over the last quarter century ${ }^{2}$, its use is still remarkably rarer than traditional VARs.

In this paper, I take a macroeconometric approach to the institutions-development debate. I build a panel structural vector autoregression (SVAR) model from equations estimated with Arellano-Bond's generalized method of moments/instrumental variables (GMM/IV) technique for 119 countries over 10 years.

The advantages of this approach are manifold. By using Arellano-Bond, it estimates unbiased fixed-effects average coefficients for short panels $(N>T)$. The results, then, control for all the time-invariant characteristics that are usually considered in the development literature. They include, for instance: latitude, access to sea, temperature, humidity, language, culture of colonizing power, initial income, etc.

This approach permits the calculation of unbiased impulse response functions (IRFs), which takes full advantage of the information contained in the cross sectional dimension of the sample. Finally, as with any VAR-approach, the model assumes endogeneity of the all variables in the system and can estimate dynamics of purely exogenous shocks.

Using the Economic Freedom of the World Index as a proxy for institutions, I find that exogenous shocks to institutional quality have a positive and statistically significant effect on GDP per capita. On average, a 1 percent shock in institutional quality, as measured by this proxy index, leads to a peak 1.7 percent increase in GDP per capita after six years. Such peak response is robust to using a different proxy for institutions (the Corruption Perception Index). There are different dynamics for advanced and developing countries, suggesting diminishing returns to institutional quality improvements.

\footnotetext{
${ }^{2}$ See Canova and Ciccarelli (2013) for a comprehensive literature review.
} 


\section{Methodology}

I estimate the following model:

$$
\begin{aligned}
B y_{i, t} & =f_{i}+A(L) y_{i, t-1}+e_{i, t} \\
i & =[1, \ldots, 119]^{\prime}, \quad t=[2002, \ldots, 2012]^{\prime}
\end{aligned}
$$

where $y_{i, t}=\left[c_{i, t}, k_{i, t}\right]^{\prime}$ is a bi-dimensional vector of stacked endogenous variables, $c_{i, t}$ is the $\log$ of GDP per capita in constant 2005 U.S. dollars, $k_{i, t}$ is the proxy for institutional quality, $f_{i}$ is a diagonal matrix of time-invariant individual-specific intercepts, $A(L)=\left(\sum_{j=0}^{p} A_{j} L^{j}\right)$ is a polynomial of lagged coefficients, $A_{j}$ is a matrix of lagged coefficients, and $e_{i, t}$ is a vector of stacked residuals, and $B$ is a matrix of contemporaneous coefficients.

Since $f_{i}$ is correlated with the error term in dynamic panels, estimation through OLS leads to biased coefficients (cf. Nickell, 1981). To avoid this, I estimate a system of $m=2$ equations with Arellano-Bond's GMM/IV technique ${ }^{3}$. Each equation has the first difference of an endogenous variable on the left hand side and $p$ lagged first differences of all $m$ endogenous variables on the right hand side.

$$
\begin{aligned}
\Delta y_{1, i, t} & =\sum_{j=1}^{p} \gamma_{11}^{j} \Delta y_{1, i, t-j}+\cdots+\sum_{j=1}^{p} \gamma_{1 m}^{j} \Delta y_{m, i, t-j}+e_{1, i, t} \\
& \vdots \\
\Delta y_{m, i, t} & =\sum_{j=1}^{p} \gamma_{m 1}^{j} \Delta y_{1, i, t-j}+\cdots+\sum_{j=1}^{p} \gamma_{m m}^{j} \Delta y_{m, i, t-j}+e_{m, i, t}
\end{aligned}
$$

In its equivalent vector moving average representation (VMA), the Panel SVAR model can be rendered as follows:

$$
B y_{i, t}=\Phi(L) e_{i, t-1}
$$

where $\Phi(L)=\sum_{j=0}^{\infty} \Phi_{j} L^{j}=\sum_{j=1}^{\infty} A_{1}^{j} L^{j}$ is a polynomial of reduced-form responses to innovations and $\Phi_{0}=A_{1}^{0} \equiv I_{m}$.

To recover the $B$ matrix and identify the model, I first calculate the variance-covariance matrix $\Sigma_{e}=E\left[e_{i, t} e_{i, t}^{\prime}\right]$. Since $B^{-1} e_{i, t}=u_{i, t}$, then $\Sigma_{e}=E\left[B u_{i, t} u_{i, t}{ }^{\prime} B^{\prime}\right]$. As the structural residuals $u_{i, t}$ are assumed to be uncorrelated $\left(u_{i, t} u_{i, t}{ }^{\prime}=I_{m}\right)$, I derive the $B$ matrix by decomposing the variance-covariance matrix into two triangular matrices.

\footnotetext{
${ }^{3}$ As explained in Arellano and Bond (1991), the GMM estimators assume $E\left[e_{m, i, t} \mid Z\right]=0$, where $Z$ is a matrix of instruments which are orthogonal to the error terms, namely lags the variables in the right hand side. For each equation, the moment estimators will minimize the above assumption by changing the symmetric matrix $M$ in $\left[\left(X^{\prime} Z M Z^{\prime} X^{\prime}\right)^{-1} X^{\prime} Z M Z^{\prime} Y^{\prime}\right]$ where $X$ is a matrix of all lagged variables on the right hand-side and $Y$ is a vector of the variable on the left-hand side.
} 
To identify the model, I need to impose one restriction to orthogonalize the contemporaneous responses. I choose to exogenize GDP per capita, by imposing that institutional quality has no contemporaneous effect on the former while GDP per capita is allowed to contemporaneously impact institutional quality. By construction, this reduces the short-term impact of institutional quality on GDP per capita, so this design is more robust if one is trying to test the institutional hypothesis.

In recovering the impulse responses from the matrices, I follow the method explained by Lutkepöhl (2007). Take the following rendering of the VMA representation of the Panel SVAR:

$$
\begin{aligned}
B M(L) y_{i, t} & =e_{i, t} \\
B y_{i, t} & =M(L)^{-1} e_{i, t}
\end{aligned}
$$

where $M(L) \equiv\left(I_{m}-\sum_{j=1}^{\infty} A_{j} L^{j}\right)$. Since $B y_{i, t}=\Phi(L) e_{i, t}$, it follows that $M(L)^{-1}=\Phi(L)$ and $M(L)^{-1} \Phi(L)=I_{m}$. After factorizing the identity and truncating the impulse horizon to $h$ periods, I can recover matrices of marginal responses $\Phi_{j}$ recursively:

$$
\Phi_{h}=\sum_{i=1}^{h} \Phi_{h-i} A_{h}
$$

To recover structural shocks, I multiply all $\Phi_{h}$ by $B^{-1}$ and then use a bi-dimensional impulse vector $s \equiv[1,0]^{\prime}$ to construct a matrix $P$ of structural responses:

$$
P=\left[\begin{array}{c}
B^{-1} \Phi_{0} S \\
B^{-1} \Phi_{1} s \\
\vdots \\
B^{-1} \Phi_{h} s
\end{array}\right]_{h x m}
$$

Collecting the first column into a vector $\left(\rho^{1} \equiv\left[\rho_{11}, \ldots, \rho_{h 1}\right]^{\prime}\right)$, I have the IRF of the of the first endogenous variable to a shock in the first endogenous variable. I then repeat the process until the $m^{t h}$ variable $\left(\rho^{m} \equiv\left[\rho_{1 m}, \ldots, \rho_{h m}\right]^{\prime}\right)$ and change the impulse variable by replacing vector $s$ above. After recovering the point estimates of all the IRFs, I calculate standard errors nonparametrically through a simulation algorithm with 1000 repetitions (see Appendix for details).

\section{DATA}

I use GDP per capita data in constant 2005 U.S. dollars from the World Bank's World Development Indicators as the income variable and the Fraser Institute's Economic Freedom of the World Index (EFW) as a proxy for institutional quality. The index takes into account five institutions-related subcomponents, namely: legal system reliability, monetary stability, burden of regulation, size of government, and freedom to trade internationally ${ }^{4}$

\footnotetext{
${ }^{4}$ See Gwartney, Lawson, and Hall (2014).
} 
I chose EFW for two reasons. First, it is significantly correlated with the risk of appropriation index AJR used in their original paper ( $t$-stat $>7)$. It is also correlated to other potential proxies for institutions, such as the Economist Intelligence Unit's Democracy Index or Transparency International's Corruption Perception Index (CPI), which was used in the robustness section. In fact, the first principal component of those four indices explain about $70 \%$ of the total variance, suggesting that those different metrics are measuring similar underlying characteristics. If the index AJR used in their paper or any of the other indices mentioned are a good proxies for institutions, so should be the EFW index.
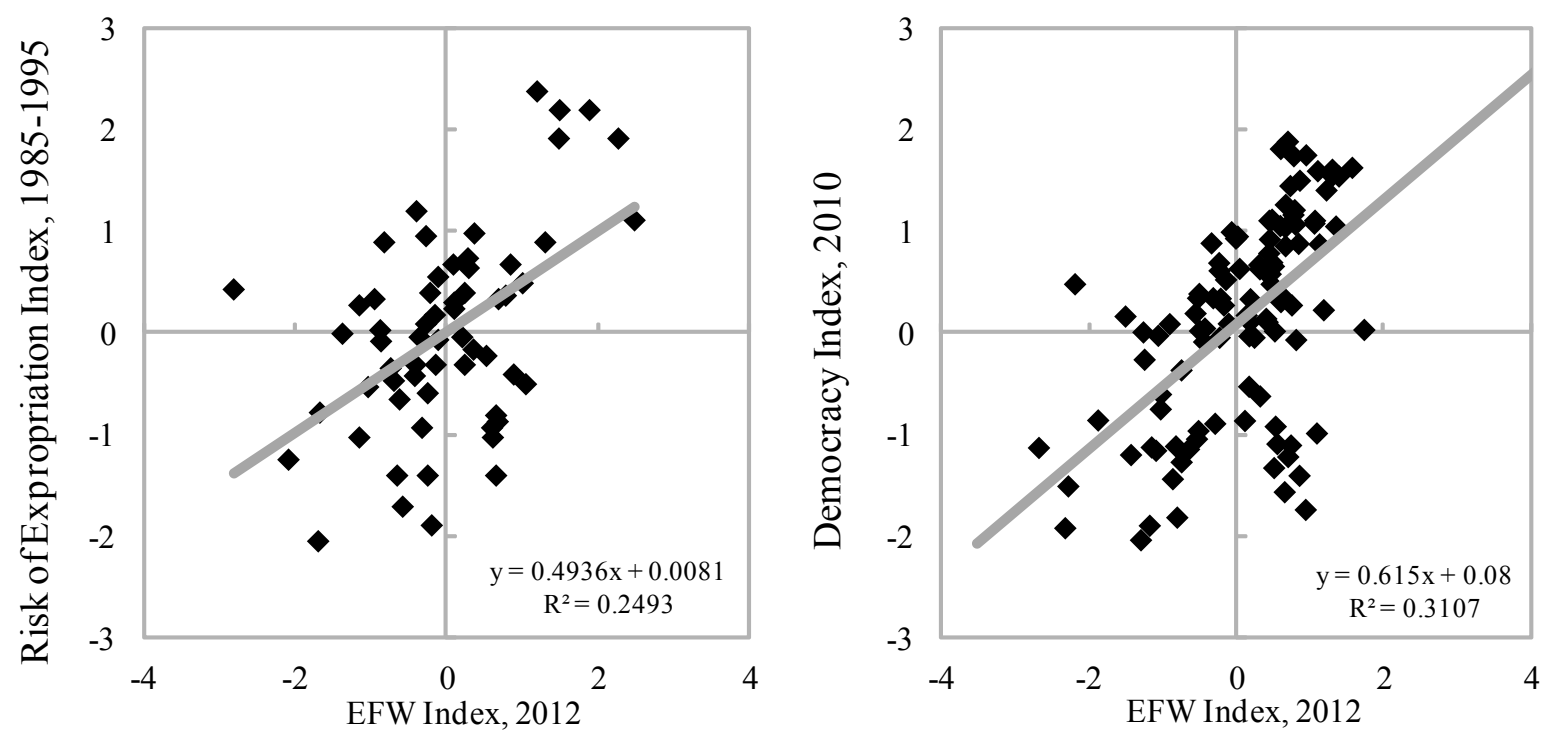

Figure 1. Correlation between EFW index and Risk of Expropriation index (AJR's sample, $n=61)$ and between EFW index and Economist Intelligence Unit's Democracy Index $(n=107)$. Variables were standardized, so the scale is in standard deviations. In all indices, a higher score means better institutions.

Second, it provides a continuous annual time series between 2000 and 2012 for a very wide range of countries. Since the Arellano-Bond estimators perform better on short panels (i.e., panels with large $N$ and small $T$ ), I wanted to take advantage of the information available from the variability between individuals as much as possible. The large cross sectional dimension of the EFW index fits suit.

The data are organized into a panel of 119 countries and 12 years. The Arellano-Bond framework implies a necessity to transform the data into first differences and use lagged instruments. For such reason, the final estimation sample drops to 10 years, resulting a total of 1190 observations.

\section{Results}

The results from the estimated GMM/IV Panel VAR are average responses of endogenous variables to an exogenous shock in any variable after controlling for time-invariant 
characteristics of individual members. It takes into consideration all the simultaneous dynamics in the system. Since the Panel SVAR is stable, over the long run shocks converge to zero. This means that shocks are temporary and over the long run the series return to their deterministic trends.

It is not obvious what a shock in institutional quality is. Such shock is an innovation in institutional quality as captured by the proxy of choice. Taking the EFW index as a proxy, the institutional gap between Nicaragua and Costa Rica, for instance, is about $10 \%$. Similarly, Burundi is about $30 \%$ below Rwanda. The results in this section suggest improvements in institutions can lead to higher income per capita, which is also observed in the contemporaneous correlation between the two variables, as seen in Figure 2 below. The standard deviation in changes in the institutions proxy is $3.5 \%$ and the average annual improvement is $0.4 \%$.

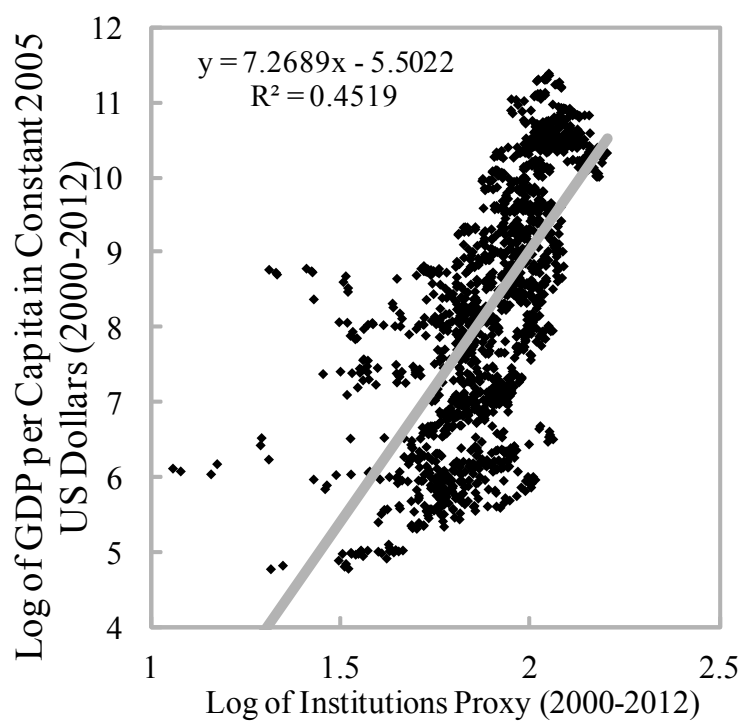

Figure 2. Contemp oraneous correlation between EFW index and GDP per capita. The chart includes all time periods for all countries $(N T=1571)$

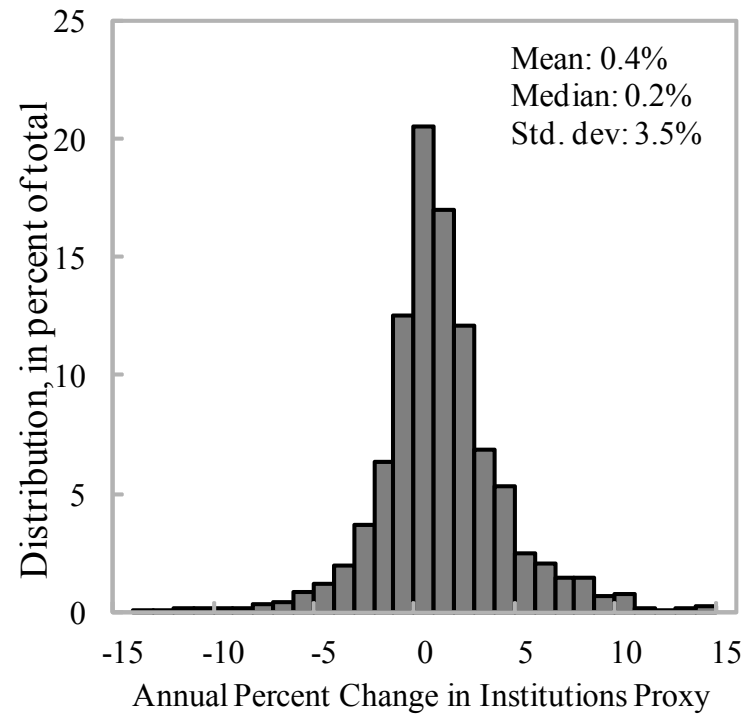

Figure 3. Distribution of Annual Percent Changes in Institutions Proxy $(N T=1450)$

I find that, on average, a 1 percent temporary shock in institutional quality leads to a peak 1.7 percent increase in GDP per capita after six years ${ }^{5}$. The relationship remains positive and statistically significant up until up to 10 years after the shock, though decreasingly so. After the fourth year, uncertainty increases rapidly - as shown by the broadening confidence bands.

\footnotetext{
${ }^{5}$ The standard-deviation of reduced-form (structural) shocks is $4.7 \%(7.5 \%)$ and $4.2 \%(6.8 \%)$ for GDP per capita and the institutions proxy, respectively.
} 

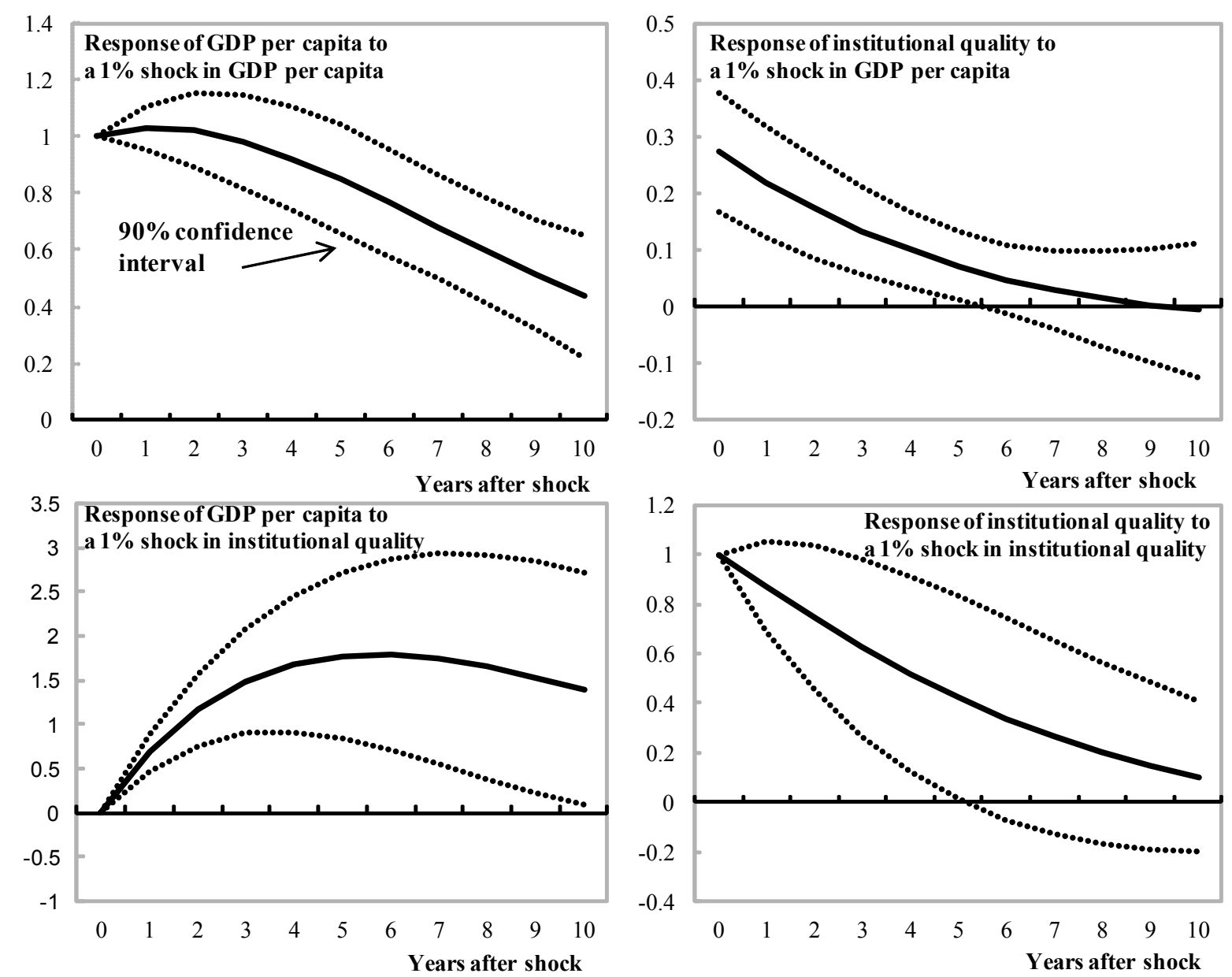

Figure 4. Impulse Response Functions, Full Sample. Calculated from GMM/IV Panel VAR $(\mathrm{N}=119, \mathrm{~T}=10)$. Standard errors from re-sampling simulation with 1,000 repetitions.

One of the setbacks of the GMM/IV approach is that it imposes homogeneous dynamics across individuals. To address this shortcoming, I split the sample between advanced and developing countries. I find that, as expected, the dynamics are indeed different among different country groups.

When restricting the sample to 25 advanced economies, the impact of improved institutional quality in GDP per capita is much smaller than observed in the whole sample, peaking at 0.35 percent two years following a 1 percent shock. Interestingly, after shocks both on GDP per capita and on institutional quality, institutional quality quickly returns back to its trend. Results are in Figure 5 below. 

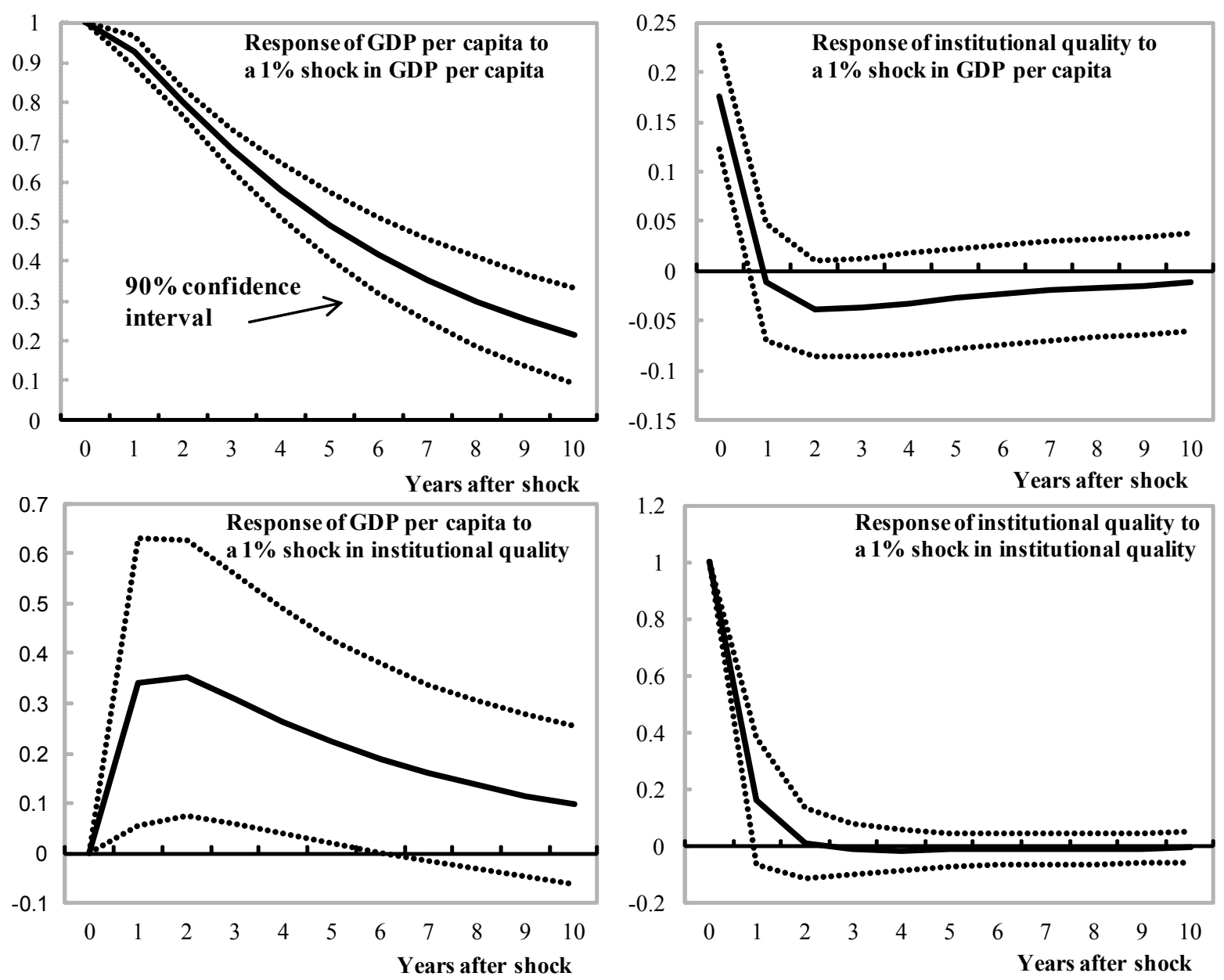

Figure 5. Impulse Response Functions, Advanced Economies. Calculated from GMM/IV Panel VAR $(\mathrm{N}=25, \mathrm{~T}=10)$. Standard errors from re-sampling simulation with 1,000 repetitions.

This is strikingly different from the results of estimating the model with the remaining 94 developing countries. For developing countries, the peak statistically significant response is 2.6 percent. Standard errors are much larger throughout all responses, which is expected, since developing countries tend to be more heterogeneous than advanced economies. 

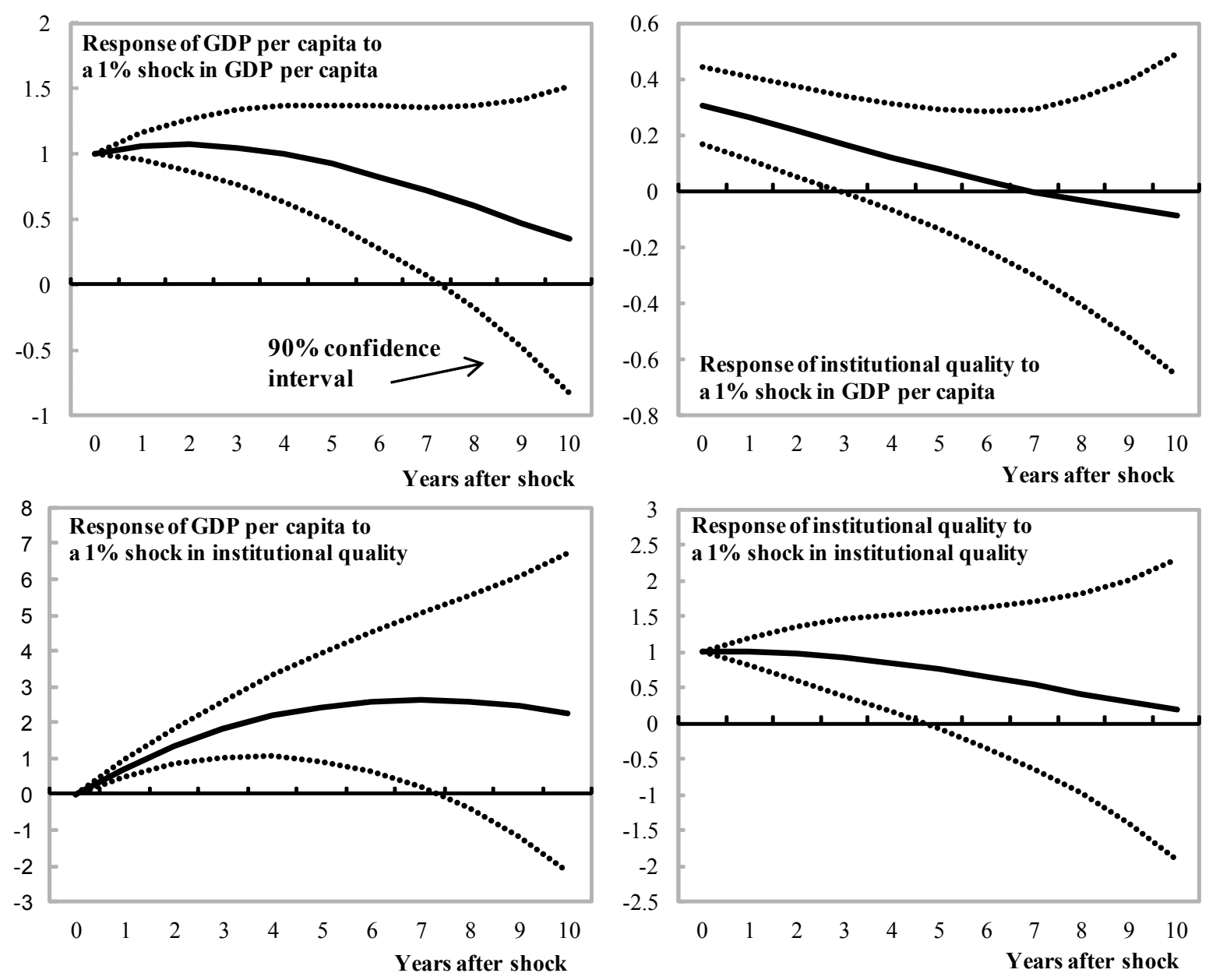

Figure 6. Impulse Response Functions, Developing Countries. Calculated from GMM/IV Panel VAR $(\mathrm{N}=94, \mathrm{~T}=10)$. Standard errors from re-sampling simulation with 1,000 repetitions.

\section{ROBUSTNESS}

I test the robustness of the results by replacing the proxy for institutions used in the baseline model. The model design and specification is the same. I replace EFW with the Transparency International's Corruption Perception Index (CPI), which is a composite index that tries to assess how fair, trustworthy and transparent government in different countries are. When using the CPI as the proxy the response of income to innovations in institutions is also positive and statistically significant.

The peak response of GDP per capita to a 1 percent shock in institutional quality leads is 1.3 percent, slightly smaller than the baseline model. Conversely, peak response of institutional quality to a 1 percent shock in GDP per capita is 0.35 percent, slightly larger than the baseline. They both fall well within the 90 percent confidence interval of the baseline model. I present results in the charts below. 

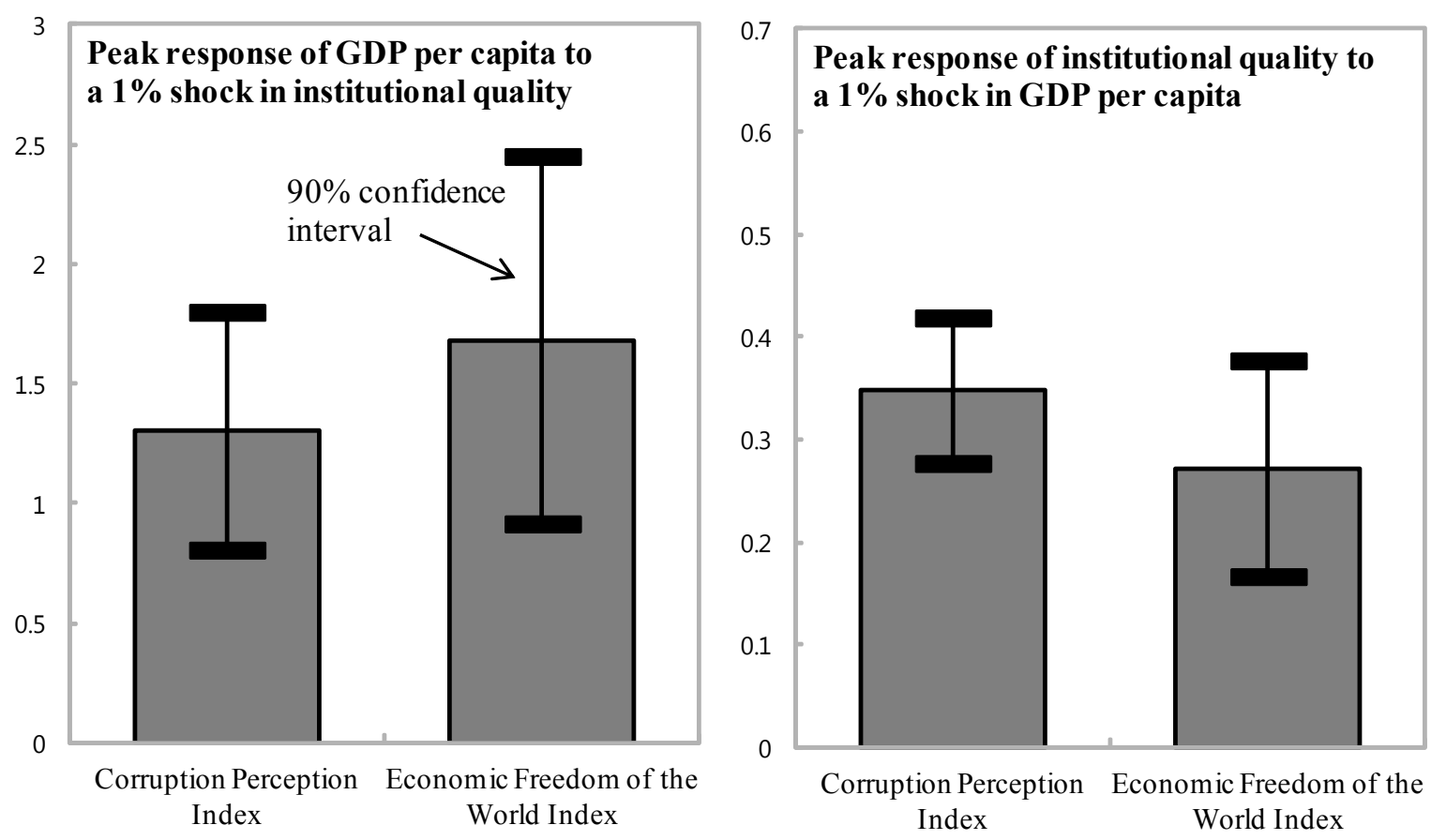

Figure 7. Robustness checks: Peak Responses. Standard errors from re-sampling simulation with 1,000 repetitions.

Measuring institutional quality can be problematic, but the consistency in the direction of responses using different proxies suggest that, qualitatively, the relationship between institutions and growth are similar. Such qualitative result is more important than the magnitude of the responses themselves.

\section{Conclusion}

I find evidence that exogenous improvements in institutional quality have positive and statistically significant impact on GDP per capita. The model controls for all time-invariant individual characteristics which are usually taken as controls in the economic development literature, does not suffer with endogeneity problem, and is robust to using a different proxy for institutions. Moreover, different proxies tend to be significantly correlated, which suggests results would not be qualitatively different when replacing proxies.

This novel approach supports the institutions hypothesis in determining development and provides evidence for bi-directional causality between institutions and growth. Additionally, the heterogeneous responses between advanced and developed economies suggest diminishing returns to institutional quality improvements, which is consistent with standard income convergence intuition. Countries with higher GDP per capita tend to have higher institutional quality, but for those countries the payoff in terms of (percentage) increase in GDP per capita is smaller. By symmetry, developing countries have higher payoffs when improving institutional quality. 


\section{Appendix}

I use a resampling algorithm with the following steps:

1. I draw a random $k$-dimensional vector $r \equiv\left[r_{1}, \ldots, r_{k}\right]^{\prime}$, where $r \in Z$ and all $r_{k}$ follow a discrete uniform distribution $U\{1, \ldots, N\}$, where $N=119$ is the number of crosssections in the sample. I set $k$ to 10 percent of the sample size plus one cross-section $(k=.1 N+1)$ and truncate the result by discarding any decimal points.

2. I exclude $k$ cross-sections from our original sample, thus restricting the sample to $T(i-k)$ observations.

3. I re-estimate the model with the restricted sample, collect the matrices of responses, extract individual vectors for each IRF and organize the simulated IRFs into a separate matrix for each $m$ endogenous variable.

4. After I repeat this procedure $n=1000$ times the result will be two distribution matrices $D$ :

$$
D_{m}=\left[\begin{array}{ccc}
\tilde{\rho}_{1 m}^{1} & \cdots & \tilde{\rho}_{1 m}^{n} \\
\vdots & \ddots & \vdots \\
\tilde{\rho}_{h m}^{1} & \cdots & \tilde{\rho}_{h m}^{n}
\end{array}\right]
$$

where $m$ is the $m^{\text {th }}$ response variable, $h$ is the response horizon, and $n$ is the number of repetitions of the simulation exercise.

5. From $D_{m}$ I take the square root of the second moment of each row to build a vector of standard errors:

$$
\sigma_{\rho_{m}}=\left[\begin{array}{c}
\operatorname{Var}\left[\left\{\tilde{\rho}_{1 m}^{1}, \ldots, \tilde{\rho}_{1 m}^{n}\right\}\right]^{\frac{1}{2}} \\
\vdots \\
\operatorname{Var}\left[\left\{\tilde{\rho}_{h m}^{1}, \ldots, \tilde{\rho}_{h m}^{n}\right\}\right]^{\frac{1}{2}}
\end{array}\right]
$$




\section{REFERENCES}

Acemoglu, Daron, Simon Johnson, and James A. Robinson, 2001, "The Colonial Origins of Comparative Development: An Empirical Investigation," The American Economic Review, Vol. 91 No. 5.

Arellano, Manuel and Stephen Bond, 1991, "Some Tests of Specification for Panel Data: Monte Carlo Evidence and an Application to Employment Equations," The Review of Economic Studies, Vol. 58 No. 2.

Canova, Fabio and Matteo Ciccarelli, 2013, "Panel Vector Autoregression: A Survey," Working Paper 1507, European Central Bank.

Eldridge, Madeline, 2013, “The Smithian Roots of the Institutions Hypothesis," George Mason University, Mimeo.

Gwartney, James, Robert Lawson, and Joshua Hall, 2014, "Economic Freedom of the World: 2014 - Annual Report," (Vancouver: Fraser Institute).

Lutkepöhl, Helmut, 2007, "New Introduction to Multiple Time Series Analysis,"'( Berlin: Springer).

Nickel, Stephen, 1981, "Biases in Dynamic Models with Fixed Effects," Econometrica, Vol. 49. No. 6, pp. 1417-26.

Sachs, Jeffrey, 2003, “Institutions Don't Rule: Direct Effects of Geography on Per Capita Income,” NBER Working Paper No. 9490 (Cambridge, Massachusetts: National Bureau of Economic Research). 